\title{
Investigating Attitudes of Adult Educators towards Educational Mobile Media and Games in Eight European Countries
}

\author{
Muhammet Demirbilek \\ Suleyman Demirel University, Isparta, Turkey
}

mdbilek@sdu.edu.tr or mdbilek@gmail.com

\section{Executive Summary}

The purpose of this research was to investigate adult educators' attitudes and perceptions of the current use of technology, mobile devices, and educational games in adult education, which is defined as any formal or informal education or training aimed at an adult population that is older than traditional university students. Learning styles and needs of adults vary. Some will be active learners and want to do things, and others will be passive and want to be told the answers. Experience, personality, and prior knowledge have an effect on the learning styles. Regardless, digital games can be tailored to engage all types of adult learners. Researchers emphasize how digital games influence the learning processes of students, as well as their effects on the educational process in general (Gee, 2004; Kafai, 1998; Prensky, 2001; Squire \& Jenkins, 2003). Basic elements of game play, such as intrinsically motivating, effectively engaging, and immersive (de Feritas, Savill-Smith, \& Attewell, 2006; Maleno, 1981), make digital games a potential and powerful learning activity. In addition to the basic elements of digital games, mobile game play has portability, connectivity social interactivity, context sensitivity, and individuality characteristics (Klopfer, Squire, \& Jenkins 2002). The ubiquitous future of mobile devices provides unique opportunities for context- and content- aware ubiquitous learning in everyday life. With the recent advent of $3 \mathrm{G}$ smart mobile devices mobile media learning is gaining more ground and receiving ongoing attention in both formal and informal learning environments. Furthermore mobile games are increasingly becoming popular among students, regardless of their age, due to fast diffusion of mobile devices and improvement of their technologies.

A fundamental survey was conducted among adult educators (We are using the term "adult educators" to mean educators of adults.) in eight European countries to outline the current state of adult educators' attitudes and perceptions toward the use of mobile games in education. Our goal was to discover emerging trends and future directions. We collected 113 surveys from eight European countries. he results of this study show that, while some adult educators do not employ any technology in their classes, in general, adult educators are aware of the use of technology and

Material published as part of this publication, either on-line or in print, is copyrighted by the Informing Science Institute. Permission to make digital or paper copy of part or all of these works for personal or classroom use is granted without fee provided that the copies are not made or distributed for profit or commercial advantage AND that copies 1) bear this notice in full and 2) give the full citation on the first page. It is permissible to abstract these works so long as credit is given. To copy in all other cases or to republish or to post on a server or to redistribute to lists requires specific permission and payment of a fee. Contact Publisher@InformingScience.org to request redistribution permission. present positive attitudes towards mobile media technologies. While slightly more than half of those studied used electronic games for teaching, almost all of this activity involved computers, not cell phones or similar portable devices. According to the data, adult educators prefer puzzles, quizzes, matching and simulation as game genres. They view language learning, communication 
skills, cultural themes, computer literacy and problem solving as topics that are more suitable for mobile games. Furthermore, the research reveals that most of the adult educators expressed their interest to use mobile games in their teaching. $76 \%$ of adult educators expressed their interest to use mobile devices in their learning activities. In all countries, adult educators indicated a willingness to employ electronic games on mobile devices. Half of participants (50\%) preferred synchronous games. Participants also indicated positive attitudes towards commercial games as better quality products. Furthermore $33 \%$ of subjects think that open source games would be better learning games due to the ongoing possibilities for future modification and development.

Keywords: adult education, educational technology, electronic games, mobile media learning, adult trainer, adult educator, educational games, serious games

\section{Introduction}

Recent developments in the field of mobile computing technologies have lead to a renewed interest among educators in using mobile devices (running systems like Windows Mobile or Symbian, which have many of the features of desktop computers with access to broadband internet networks) as tools for teaching and learning. Location and time independent characteristics of mobile media devices have a unique place in the next generation of learning environments. In the last decade, fast diffusion of mobile devices in society, especially mobile phones, offered great opportunities for ubiquitous learning. There is a growing research interest across the world in seeking to understand how the new wireless and mobile technologies can contribute to improving the student's experience of learning. With the recent advent of $3 \mathrm{G}$ smart mobile devices, educational mobile games are gaining more ground in both formal and informal learning environments. Learning games can be considered as a fun and challenging extension to typical learning activities and a strategy to motivate students.

The comprehensive use of information and communication technologies is leading to changes in the ways we teach and learn. Digital learning technologies have enabled a variety of ways for teachers to give instruction and students to learn that were not possible in a traditional education environment. With the recent advancement of mobile technologies, such as smart phones, cameras and PDAs (Personal Digital Assistants), numerous new opportunities arise for adult education. Mobile access to learning content provides unique opportunities for leveraging valuable experiences outside of the classroom. Digital mobile games are commonly used with children in their daily life for both educational and entertainment purposes. Today's students, who are the future's adults, will have grown up with these technologies. Well designed educational games and supporting materials can be a powerful learning medium for stimulating motivation and promoting learning (Song \& Zhang, 2008). Recent research shows that electronic games are widely used as instructional tools in schools and are becoming more a part of the students and adults' social lives (Klopfer, 2008; Roschelle, Patton, \& Pea, 2002; Squire, 2010; Squire \& Klopfer, 2007).

Little research has been done examining adult educators' perceptions and attitudes towards mobile technology and games. For purposes of this study, we define adult education as any formal or informal education or training aimed at an adult population that is older than traditional university students. Our goal in beginning this area of inquiry was to learn more about how mobile games and technological pedagogical practices are viewed by adult educators. Therefore, this research study explores adult educators' perceptions of and attitudes toward the current use of technology, mobile devices, and educational games for their own classes. Objectives of this study were to explore attitudes and perceptions of adult trainers on mobile games, to examine the extent of use and distribution of mobile devices in adult education, and to examine the preference for game genres by adult educators. The current study is part of "Implementing Learning Game Resources 
based on Educational Content" (ILGRECO) supported by the European Union Commission's Socrates program, action Grundtvig-1 within the Sixth Framework.

\section{Literature Review}

\section{Mobile Media and Learning}

The history of mobile devices ranges from graphic calculators (1970s-1980s) to today's 3G smart phones and PDAs. Mobile media have become increasingly relevant to education thanks to the widespread adoption of mobile devices in society (Wood, Lloyd, \& Ashfield, 2006). Mobile media devices are relatively inexpensive, offer the possibility of ubiquitous (anywhere, anytime) computing, can facilitate collaborative learning, and support individualized independent learning (Savill-Smith \& Kent, 2003). Mobile media are breaking down boundaries of conventional classroom by providing convenient access to anytime, anywhere, course materials to help students catch up on missed classes, prepare for homework and exams, and clarify concepts discussed in classes. Consequently, educators are increasingly seeing mobile devices as opportunities for learning. Today's youth have grown up using computers, the Internet, games, and mobile media devices, which have shaped their culture and social life. Mobile media is part of the new generation's daily life. Their learning habits are changing toward more visually rich multi-channel information and time / location independent context. Therefore, in recent years, adaptation of mobile devices in education has been increased (Roschelle, Sharples, \& Chan, 2005).

"A mobile device" refers to a pocket-size portable that is small enough to be held in one hand and can be used wirelessly (Dye, 2007). Mobile learning, generally abbreviated as m-learning, may be defined as learning opportunities offered by mobile devices such as mobile phones, handhelds, PDA, and smart phones. A mobile game can be defined as an electronic game played on a mobile phone, smart phone, PDA, handheld computer, or any type of handheld or wireless device. An educational mobile game is an engine using the characteristics of electronic games to create engaging learning experiences for delivering specified learning goals, outcomes, and experiences.

Klopfer, Squire, and Jenkins (2002) describe five characteristics of mobile devices that provide unique educational advantages for ubiquitous learning: (a) portability (location independent); (b) social interactivity (can exchange data and collaborate with others; (c) individuality (can provide scaffolding for individual paths of investigation); (d) connectivity (can connect handheld devices to other devices to create a shared environment); and (e) context sensitivity (can gather data 'justin-time and place'). These characteristics of $3 \mathrm{G}$ smart phones and PDAs provide unique opportunities to deliver learning content and engage learners who may have lost interest in education (Kukulska-Hulme, 2007; Shih \& Mills 2007; Wagner 2005). Therefore, it is easy to predict that mobile media devices may support a wide range of teaching and learning approaches from behaviorism to constructivism and social constructivism (Naismith, Lonsdale, Vavoula, \& Sharples, 2004; Yuen \& Yuen, 2008). Naismith et al. (2004) have stated six different ways that mobile media devices can be used in adopting mobile learning in constructivist, situated, collaborative, and informal learning environments. In addition, $3 \mathrm{G}$ smart phones and PDAs enable teachers to implement field based situated learning activities and allow students to take notes into a device, interacting with the context and teacher during outdoor learning activities.

Furthermore, mobile devices offer advantages in supporting approaches that can facilitate personal informal interactions from variable locations. In addition, these devices offer mobile learners opportunities to interact and communicate with their peers remotely. Research on mobile media learning reveals the potential effect of mobiles devices on informal learning practices, specifically lifelong learning and adult education applications (e.g., Bradley, Haynes, \&Boyle, 2005; Fallahkhair, Pemberton, \& Griffiths, 2005; Scanlon, Jones, \& Waycott, 2005; Vavoula, Sharples, 
O'Malley, \& Taylor, 2004). Moreover, Kukulska-Hulme and Pettit (2008) argue that the rising importance of informal and lifelong learning has a unique connection with the affordability of mobile technologies.

Mobile media enable learners to explore knowledge and situations in their own way, in a variety of places, and often outside the time constraints of traditional classroom based teaching. This attribute of mobile media supports situated learning (Stein, 1998). Mobile media devices also increase learner motivation, provide for an interactive and engaging learning environment, facilitate control of the learning process, and emphasize its relationship with the real world (Zurita \& Nussbaum, 2004). Furthermore, Rekkedal and Dye (2007) investigated experiences from the development and testing of mobile learning integrated with the online distance education system in Norway. They suggest that better, more flexible mobile solutions are needed to serve distance learners studying online with mobile devices. Moreover, they found that courses must be developed, presented, and distributed in a manner that allow both mobile and non-mobile distance learners to participate in the same course, using the same course materials that can be accessed from standard and mobile technologies.

\section{Game Based Learning}

Educational electronic games (often called serious games) can be defined as a rule-guided competition engaged in by one or more players. The purpose of a serious game is to train or teach while entertaining the learner. Electronic games put players in the role of decision maker and provide learners with engaging and challenging environments in which to solve problems (Kim, Park, \& Baek, 2009). Game play may include rules, goals, outcomes, feedback, conflict, challenge, competition, interaction, and narrative (Prensky, 2001). Research about how digital games influence the learning processes of the student has increased since the late 1990s. The pedagogical role of electronic games in education has been widely documented (e.g., Gee, 2004; Kafai, 1998; Klopfer, 2008; Prensky, 2001; Squire \& Jenkins, 2003). Game play is intrinsically motivating, effectively engaging, and immersive (de Feritas et al., 2006; Malone, 1981). These elements make game play a powerful learning activity. The "fun-flow" experience can be facilitated by games (Malone \& Lepper, 1987). Flow state has positive impact on learning (Csikszentmihalyi, 1991).

Kovalik and Kovalik (2008) investigated the history of gaming, how rules are interpreted by scholars, how behavioral psychology influences gaming, and how individuals strategize through gaming. A card game was introduced to a freshman composition class, and the results were gathered from their observations and interviews. The results showed that students preferred preconceived rules over free play. The researchers linked this to real life and law. Furthermore Young and Upitis (1999) state that students' visual processing skills and the ability to manipulate objects or mental images through space can be enhanced by playing computer games. Digital games and simulations are flexible and complex enough to provide for different learning styles (Kirriemuir 2002). Learning benefits attributed to computer games in educational settings are: (a) supports constructivist learning (Whitton, 2007), (b) motivates learner (Bixler, 2005), and (c) encourages learners who may lack interest or confidence (Klawe, 1994).

The use of technology in adult education is not new. Throughout the $20^{\text {th }}$ century developments and changes in instructional technology have had impacts on education. Successive waves of technological innovations have forced changes in conventional methods and tools of traditional education. Both adult educators and adult students had to adapt themselves to these unprecedented developments of information and communication technologies. Mobile tools such as mobile phones have recently become parts of adults' everyday life. Therefore, mobile technologies are also considered a new learning medium for adult education. Thanks to their motivation effect, mobile games can be a good fit for adult learners who can easily get bored during the learning 
process (Miettunen \& Mattila, 2007; Terehoff, 2002). However, at present, little empirical research has been conducted on adult educators' perception and attitudes toward mobile devices and educational games on their own adult education.

The purpose of this research is to investigate adult educators' attitudes and perceptions on the use of technology, specifically the use of mobile devices and educational games in adult education in eight European countries. Objectives of the study were:

(a) To explore the attitudes and perceptions of adult educators regarding the use mobile games with educational features in adult education in eight European Countries,

(b) To examine the extent of use and distribution of mobile devices on adult education,

(c) To examine adult educators' preferences preference of game genres in education.

The findings of this research will help adult education institutions to examine the role of mobile learning environments and mobile games and their feasibility in adult education as a way to supplement adult education courses from an educator's perspectives, attitudes, and perceptions.

\section{Methodology}

The survey instrument was developed and adopted to gain a deeper understanding of adult educators' attitudes and perceptions toward the use of games and mobile devices in adult education. The survey was developed by the coordination of project partners in terms of the necessities of adult educators. Think-tank meetings were held to debate emerging key survey questions with experts who have been working in wireless and mobile learning for several years. The survey instrument was reviewed and then revised by experts for content validity. To improve reliability and to assess the ease of understanding of the survey items, the survey was pilot tested on 8 project partners who were educators at adult education institutions before collecting the data. After the results of the minor survey were received, changes were made.

The survey instrument was a questionnaire with eleven items with closed-ended unordered response choices and partly-closed ended questions to retrieve subjects' perceptions and attitudes toward the use of mobile media and electronic games in education. Educational research commonly uses surveys to measure attitudes and perceptions (Al-Fahad, 2009; Chao, 2006). The study was conducted in eight European countries: Cyprus, Bulgaria, Hungary, Italy, Lithuania, Romania, Spain, and Turkey. Table 1a shows country names and codes. Because of easy access by project partners, participants were selected from the partner countries. The subjects were informed that participation in the study was voluntary.

Table 1a. Country names and codes

\begin{tabular}{|l|c|c|c|c|c|c|c|c|}
\hline $\begin{array}{l}\text { Country } \\
\text { Names }\end{array}$ & Bulgaria & Cyprus & Spain & Hungary & Italy & Lithuania & Romania & Turkey \\
\hline $\begin{array}{l}\text { Country } \\
\text { Codes }\end{array}$ & BG & CY & ES & HU & IT & LT & RO & TR \\
\hline
\end{tabular}

The questionnaire was translated into the language spoken in each country by the project partners. Subjects were asked to complete the survey through face to face encounters, e-mail messages, and phone contacts. The questionnaire, including a cover letter, was distributed to participants during a month. All participants were asked to respond to the questionnaire and their responses were guaranteed confidentiality. Respondents of the survey were adult educators at formal and informal adult education institutions. The formal and informal adult education institutions consist of local public education and training centers, continuing education centers, private adult education 
and training centers, and vocational training centers. The subjects the adults studying were Introduction to ICT, Computer Literacy, English as a Second Language, Introduction to Microsoft Office (Excel, Word, \&Power Point), Web Design, etc. Descriptive statistic was employed to analyze the data. A total of $113(\mathrm{~N})$ filled surveys were collected from targeted adult educators who are experienced practitioners working at adult education institutions. Fifty-four percent (54\%) of participants were male and forty-six (46\%) were female. Participant's age range was from 25 to 54. The relation between respondents' gender and country are presented in Table $1 \mathrm{~b}$. All the adult educators who participated in the survey owned a cellular phone or other type of mobile device such as PDAs, handhelds and smart phones. This highlights an important issue to be considered in any future mobile media based learning and game applications.

Table 1b: Relation between respondents' genders and country

\begin{tabular}{lcccccccc}
\hline Country & BG & CY & ES & HU & IT & LT & RO & TR \\
\hline $\begin{array}{l}\text { Number of } \\
\text { Participants }\end{array}$ & 11 & 5 & 10 & 10 & 10 & 13 & 21 & 33 \\
\hline Female (\%) & 64 & 0 & 40 & 80 & 10 & 77 & 38 & 18 \\
\hline Male (\%) & 36 & 100 & 60 & 20 & 90 & 23 & 62 & 82 \\
\hline
\end{tabular}

\section{Results}

Detailed results will now be presented using percentages for each country. Care should be taken when generalizing these results to any entire country, however, because of the relatively small number of responses from any one individual country, as shown earlier in Table $1 \mathrm{~b}$.

\section{Technology Use in Adult Education}

The questionnaire began with a general question: Do you use technology within your institution for adult education? The question was aimed at defining general technology use in eight countries. The results showed that the majority of the respondents are using technology in their education. While $93 \%$ of participants stated that they are employing technology, $7 \%$ of participants pointed that technology is not used in their adult education activities. According to the results, all participants from Spain, Cyprus, Italy, Bulgaria, and Turkey stated that they are integrating technology in their education activities. The variations from 10 to 23 percent of non-users are indicated in Lithuania, Romania, and Hungary. Table 2 shows the percentage distribution in each country.

Table 2: Distribution of technology use

\begin{tabular}{cccccccccc}
\hline & Country & BG & CY & ES & HU & IT & LT & RO & TR \\
\cline { 2 - 9 } $\begin{array}{c}\text { Do you use technology } \\
\text { within your institution for } \\
\text { adult education? }\end{array}$ & Yes (\%) & 100 & 100 & 100 & 90 & 100 & 85 & 73 & 100 \\
\cline { 2 - 9 } & No (\%) & 0 & 0 & 0 & 10 & 0 & 15 & 23 & 0 \\
\hline
\end{tabular}

\section{Use of Electronic Games for Adult Education}

The second question aimed at defining how widely electronic games are used in adult education. Data in Table 3 provides an overview of game use in education. The respondents' data showed that almost 54 percent of participants use electronic games in their education. However, the data 
shows variations among the countries. The highest rate of game use by adult educators was observed in Spain, Cyprus and Bulgaria. Romanian and Hungarian respondents indicated that they are not using games in their education. Table 3 shows the distribution of electronic game use for adult education among countries.

Table 3: Distribution of electronic game use

\begin{tabular}{lccccccccc}
\hline & Country & BG & CY & ES & HU & IT & LT & RO & TR \\
\cline { 2 - 10 } $\begin{array}{l}\text { Do you use electronic } \\
\text { games for education? }\end{array}$ & Yes (\%) & 64 & 60 & 60 & 10 & 50 & 46 & 32 & 49 \\
\cline { 2 - 9 } & No (\%) & 36 & 40 & 40 & 90 & 50 & 54 & 68 & 51 \\
\hline
\end{tabular}

Adult educators generally perceive game use as a facilitating factor during education for both motivating and entertaining the adult students. Most of their education curricula do not include game based lesson plans and activities. There are several reasons for this. First, there is a lack of appropriate educational games for adult learners. Second, most of educational games on the market are in English, and trainers are reluctant to use games that are not in their spoken language.

\section{Type of Technology used for Electronic Games}

Respondents were asked to specify types of technology used in their education. The majority identified desktop computers and notebooks (respectively 58\% and 30\%) as the most used technology tools for gaming; 10 percent of respondents identified using mobile tools such as pocket PC $(2 \%)$, iPod $(2 \%), 3 \mathrm{G}$ phones $(6 \%)$. It is clear that mobile devices are not dominantly employed for gaming purposes. Even a basic search for the internet based game would reveal that the number of educational games released for mobile devices remains small compared to commercial games. Therefore, it would be easy to predict that the use of mobile devices is not common for learning games in adult education.

\section{The Use of Mobile Devices for Electronic Games in Adult Education}

Participants were also asked about the use of mobile devices in their teaching. 7\% of participants said they use mobile devices to facilitate electronic games in their education. The interpretation of this data shows that the use of mobile devices in adult education is relatively low. A small number of adult educators use mobile devices in their education. The country data shows that the majority of participating countries don't use mobile devices in adult education (Lithuania, Spain, Cyprus, Bulgaria, and Hungary). The positive experience identified in Romania, Italy, and Turkey is a relatively small percentage (Table 4).

Table 4: The percentage of the use of mobile devices for electronic games in adult education according the country data

\begin{tabular}{|c|c|c|c|c|c|c|c|c|c|}
\hline \multirow{3}{*}{$\begin{array}{l}\text { Do you use mobile devices for } \\
\text { electronic games in adult } \\
\text { education }\end{array}$} & Country & $\mathrm{BG}$ & $\mathrm{CY}$ & ES & $\mathrm{HU}$ & IT & $\mathrm{LT}$ & $\mathrm{RO}$ & TR \\
\hline & Yes $(\%)$ & 100 & 100 & 100 & 100 & 50 & 100 & 80 & 86 \\
\hline & No $(\%)$ & 0 & 0 & 0 & 0 & 0 & 0 & 20 & 14 \\
\hline
\end{tabular}




\section{Operating Systems}

Participant's responses to the type of operating system (OS) mobile devices run revealed that the two major operating systems were identified as Windows Mobile and Symbian. According to results, adult educators are more familiar with Windows Mobile OS than other operating systems such as Symbian, and Linux mobile.

\section{Game Genres}

Subjects were asked to identify what kind of electronic game genres they prefer for their education purposes. The results showed that the majority of trainers prefer puzzles (18\%), quizzes $(16 \%)$, matching $(12 \%)$, and simulation (12\%), if they have the opportunity to use mobile games in their teaching. Alternate reality games were rated as less in terms of usage. Table5: shows a chart distribution of the game types according to their usage by adult educators.

Table 5: Game types and their usability for educational purposes

\begin{tabular}{|c|c|c|c|c|c|c|c|c|c|c|c|c|c|}
\hline Genre & Puzzle & Quiz & Sim & Matching & Strategy & A\&A & RPG & Maze & RTS & TBS & FPS & ARG & Other \\
\hline$\%$ & 18 & 16 & 12 & 12 & 11 & 9 & 6 & 5 & 3 & 3 & 2 & 2 & 1 \\
\hline
\end{tabular}

Sim: Simulation, A\&A: Action \& Adventure, RPG: Role playing game, RTS: Real-time strategy,

TBS: Turn-based strategy, FBS: First person shooter, ARG: Alternate reality

\section{Electronic Game Interface Preference}

$82 \%$ of survey participants consider that graphical interface is more useful and appropriate for playing games on mobile devices. Only $7 \%$ of respondents indicated that they would prefer text interface to play games on mobile devices. The electronic game interface preferences are consistent in all countries.

\section{Willingness to use Electronic Games on Mobile Devices}

The majority $(76 \%)$ of respondents would be interested in the use of mobile devices and educational games as an interface for their education activities. $18 \%$ of respondents indicated that they are not interested in using mobile games as an educational tool. The positive view is identified in all countries, while the more conservative opinions are in Bulgaria and Hungary (Table 6).

Table 6: The percentage of willingness to use electronic games on mobile devices

\begin{tabular}{|c|c|c|c|c|c|c|c|c|c|}
\hline \multirow{4}{*}{$\begin{array}{l}\text { Are you interested in testing } \\
\text { mobile devices as an interface } \\
\text { for learning games? }\end{array}$} & Country & $\mathrm{BG}$ & $\mathrm{CY}$ & ES & $\mathrm{HU}$ & IT & LT & $\mathrm{RO}$ & TR \\
\hline & Yes $(\%)$ & 55 & 100 & 70 & 60 & 70 & 85 & 82 & 86 \\
\hline & No $(\%)$ & 45 & 0 & 20 & 40 & 0 & 15 & 14 & 11 \\
\hline & NA (\%) & 0 & 0 & 10 & 0 & 30 & 0 & 4 & 3 \\
\hline
\end{tabular}

\section{Synchronous vs. Asynchronous Games}

Participants were asked if they preferred synchronous or asynchronous games on mobile devices. Half of respondents (50\%) selected synchronous games as more appropriate for educational mobile games. $12 \%$ of participants think that both synchronous and asynchronous games could be 
used for educational purposes on mobile devices. $27 \%$ of respondents indicated that they prefer asynchronous games (\%11 of subjects did not answer this question). Synchronous games were evaluated most positively in Spain, Cyprus, Romania, Hungary, Turkey, and Bulgaria. Asynchronous games are preferred more in Lithuania and Italy (Table 7).

Table 7: Participants' preference for synchronous vs asynchronous games on mobile devices

\begin{tabular}{lccccccccc}
\hline & Country & BG & CY & ES & HU & IT & LT & RO & TR \\
\cline { 2 - 9 } & Sync (\%) & 55 & 100 & 70 & 70 & 30 & 31 & 64 & 73 \\
\cline { 2 - 9 } $\begin{array}{l}\text { Which category of elec- } \\
\begin{array}{l}\text { tronic games do you } \\
\text { think is more useful on } \\
\text { mobile devices? }\end{array}\end{array}$ & Async (\%) & 36 & 0 & 20 & 20 & 50 & 46 & 27 & 27 \\
\cline { 2 - 10 } & Blended (\%) & 9 & 0 & 0 & 10 & 0 & 23 & 0 & 0 \\
\hline
\end{tabular}

Sync: Synchronous, Async: Asynchronous

\section{Commercial vs. Open Source Game Preference}

Commercial vs. open source game preference was asked. The result revealed that adult educators $(59 \%)$ believe commercial games are better quality. 33\% think that electronic games developed on open source are better. While commercial electronic games are more appreciated in Bulgaria, Hungary, Lithuania, Spain, and Romania, open source products are preferred in Cyprus, Italy, and Turkey.

\section{Adult Educational Programs, Courses and Subjects Suitable for Games Based Learning}

Participants were asked to select the most appropriate list of courses and subjects for mobile game based teaching. The result shows that language-learning and computer literacy $(18 \%$ and $15 \%$ respectively) were evaluated as more appropriate subjects for mobiles devices. Electronic games on mobile devices are seen as more suitable for language learning, improving communication skills, culture, computer literacy, and problem solving skills according to subjects preference about propriety of the suggested topics (Table 8).

Table 8: The percentage of subject evaluated as more appropriate for educational games on mobile devices

\begin{tabular}{|l|l|l|l|l|l|l|l|l|}
\hline Course & $\begin{array}{c}\text { Language } \\
\text { learning }\end{array}$ & $\begin{array}{c}\text { Computer } \\
\text { literacy }\end{array}$ & $\begin{array}{c}\text { Problem } \\
\text { solving }\end{array}$ & $\begin{array}{c}\text { Communication } \\
\text { skills }\end{array}$ & Culture & $\begin{array}{c}\text { Computer } \\
\text { programming }\end{array}$ & $\begin{array}{c}\text { Music } \\
\text { education }\end{array}$ & $\begin{array}{c}\text { Management } \\
\text { or } \\
\text { supervision }\end{array}$ \\
\hline$\%$ & 18 & 17 & 15 & 14 & 12 & 8 & 8 & 8 \\
\hline
\end{tabular}

\section{Limitations of the Study}

The current study has certain limitations that need to be taken into account. The relatively small sample size makes it difficult to draw broad generalizations from the data. Certainly no specific conclusions can be drawn about any one country. However, the research does suggest that most adult educators are interested in using mobile games in their teaching. The participants' perceptions and attitudes may change according to alterations in their environments and experiences, and repeatability may not be possible. Further, within this study, the translated text of the questionnaire may not have conveyed the intended meaning of the original text across numerous cultures and countries. The information was gathered through survey, and factors that may influence 
adult educators' perceptions, such as adult educators' ability, prior experience with technology, prior background computer games, and personality type, were not considered.

\section{Suggestions for Future Research}

Despite the contributions of this study to adult education, it is not free from limitations and caveats. Although, the respondents seem to be mostly tech-enthusiasts willing to embrace technology, they may not be representative of adult educators as a whole, or even of adult educators in their countries. The number of participants is too limited for broad generalizations. However this study may provide the basis for further empirical research to see if the results can be replicated in different contexts and surroundings.

This study was primarily intended to investigate adult educators' attitudes and perception toward mobile technologies and electronic games. The most important consideration for future work is the expansion of large data sets employed in these analyses. With larger data sets, more significant and generalized result can be established.

A follow-up study should be done about how to build the mobile game learning environment based on the result of the current study. In addition, an extensive research project should be developed to reveal the best methods of successfully using mobile games within the current education system. Furthermore, adult educators' changing confidence and competence in using mobile games, as well as their methods for using them, could also be examined through longitudinal studies. Finally, since the mobile devices are so personal, there are both challenging and important issues for educators and learners to find out how adult educators and learners are managing to use their mobile media as an instructional gaming purposes tool. There is a need to find good ways of sharing and disseminating information about making effective use of the capabilities of mobile media (3G phones, PDAs, etc) in education.

\section{Conclusions}

Mobile technologies, especially mobile phones, have indeed become commonplace tools serving a wide array of purposes that include teaching and learning alongside work and leisure. This study confirms that adult educators are willing to take advantage of the capabilities of mobile devices to meet their own needs and the needs of their students. There is potential to use mobile technologies in adult education if the content provided to adult learners is based on the suggestions of adult educators. According to the research result, adult educators describe the preferred characteristics of the electronic games as:

- An application suitable with Windows Mobile OS or other operating systems

- Graphically interfaced

- Synchronized

- Being one of these game genres: puzzle, quizzes, matching, and simulation

- Game play on the topic of language learning, communication skills, culture themes, computer literacy, or learn to solve problems

- Open source applications preferred for future improvements

- Commercial games are more appreciated in terms of quality

Adult educators' intent to use electronic games and mobile devices begins with their attitude and perception toward using them in their daily teaching and learning practices. The mobile media devices available to teachers and learners all over the world are increasing, so it is critical to measure the attitudes and perceptions of adult educators about the use of mobile technologies, in establishing appropriate interpositions that help adult educators to integrate these technologies 
into their education. Curriculum planners in adult education institutions should consider adult educators' opinions before engaging in decision-making processes concerning the integration of mobile games with educational features into adult education courses.

Thanks to mobile devices, learning can occupy a new space that gives individuals the capacity to make use of electronic resources and tools in flexible ways that suit their circumstances and lifestyles. Mobile phones are used by millions of adults on a daily basis and have great importance in providing adult students with learning both in and out of school. Providing content while employing mobile games has the potential to make learning both easier and more fun for adults, and it may improve their perception of life-long learning.

\section{Acknowledgements}

This manuscript is based on a research report from the ILGRECO project, which was kindly supported by the European Commission's Grundtvig Program under grant number: 230039-CP-12006-1-GRUNDTVIG-G11. The European Commission is not responsible for any views expressed in the paper. I would like to thank Vilma Butkute for her contributions to the report.

\section{References}

Al-Fahad, F. (2009). Students' attitudes and perceptions towards the effectiveness of mobile learning in King Saud University, Saudi Arabia. The Turkish Online Journal of Educational Technology - TOJET $8(2)$.

Bixler, B. (2005). Motivation and its relationship to the design of educational games. Paper presented at the New Media Consortium (NMC) Online Conference on Educational Gaming, Internet.

Bradley, C., Haynes, R., \& Boyle, T. (2005). Adult multimedia learning with PDAs -- The user experience. Paper presented at the Mlearn 2005 Conference, Cape Town.

Csikszentmihalyi, M. (1991). Flow: The psychology of optimal experience. New York: Harper Perennial.

Chao, C. (2006). An empirical assessment of learners' perceptions of acceptance of wireless-mobile technologies in supporting learning. In E. Pearson \& P. Bohman (Eds.), Proceedings of World Conference on Educational Multimedia, Hypermedia and Telecommunications 2006 (pp. 2662-2666). Chesapeake, VA: AACE.

de Freitas, S., Savill-Smith, C., \& Attewell, J. (2006). Educational games and simulations: Case studies from adult learning practice. London: Learning and Skills Research Centre.

Dye, A. (2007). Designing courseware for mobile devices. In D. Keegan (Ed.), Mobile learning: A practical guide. Proceedings of EADL Conference IADT, Dun Laoghaire.

Fallahkhair, S., Pemberton, L., \& Griffiths, R. (2005). Dual device user interface design for ubiquitous language learning: Mobile phone and interactive television (iTV). IEEE International Conference on Wireless and Mobile Technology for Education (WMTE). Tokushima, Japan.

Gee, J. P. (2004). What video games have to teach us about learning and literacy. New York: Palgrave Macmillan Erlbaum Associates

Kafai, Y. (1998). Video game designs by children: Consistency and variability of gender differences. In J. Cassell \& H. Jenkins (Eds.), From Barbie to Mortal Kombat: Gender and computer games. Boston, MA: MIT Press.

Kim, B., Park, H., \& Baek, Y. (2009). Not just fun, but serious strategies: Using meta-cognitive strategies in game-based learning. Computers \& Education, 52(4), 800-810.

Kirriemuir, J. (2002). A survey of the use of computer and video games in classrooms. Internal report for BECTA (British Educational Communications and Technology Agency). 
Klawe, M. M. (1994). The educational potential of electronic games and the E-GEMS project. In T. Ottman \& I. Tomek (Eds.), Proceedings of ED-MEDIA 94: World Conference on Educational Multimedia and Hypermedia. Charlottesville, VA: AACE.

Klopfer, E. (2008). Augmented learning: Research and design of mobile educational games. Cambridge. MA: MIT Press.

Klopfer, E., Squire, K., \& Jenkins, H. (2002). Environmental detectives: PDAs as a window into a virtual simulated world. Paper presented at the International Workshop on Wireless and Mobile Technologies in Education, Taiwan.

Kovalik, L. M., \& Kovalik, D. (2008). A lesson learned through gaming. Simulation \& Gaming. An Interdisciplinary Journal of Theory, Practice and Research, 29(1), 118-125.

Kukulska-Hulme, A. (2007). Mobile usability in educational contexts: What have we learned? The International Review of Research in Open and Distance Learning, 8(2).

Kukulska-Hulme, A., \& Pettit, J. (2008). Practitioners as innovators: Emergent practice in personal mobile teaching, learning, work and leisure. In M. Alley (Ed.), Empowering learners and educators with mobile learning. Athabasca University Press.

Malone, T. (1981). Towards a theory of intrinsically motivating instruction. Cognitive Science, 4, 333-369.

Malone, T. W. \& Lepper, M. R. (1987). Making learning fun: A taxonomy of intrinsic motivations for learning. In R. E. Snow \& M. J. Farr (Eds.), Aptitude, learning, and instruction: Cognitive and affective process analysis (Vol. 3, pp. 223-253). Hillsdale, NJ: L. Erlbaum Associates.

Miettunen, J., \& Mattila, P. (2007). Motivating learning in mobile and game-based environments. Experiences in everyday classroom work. The path to the School of the Future. Proceedings of the International Conference of "Interactive computer aided learning" ICL2007.

Naismith, L., Lonsdale, P., Vavoula, G., \& Sharples, M. (2004). NESTA Futurelab Series, Report 11: Literature review in mobile technologies and learning. Bristol, UK: Nesta Futurelab.

Prensky, M. (2001). Digital game-based learning. New York: McGraw-Hill.

Rekkedal, T., \& Dye, A. (2007). Mobile distance learning with PDAs: Development and testing of pedagogical and system solutions supporting mobile distance learners. International Review of Research in Open and Distance Learning, 8(2), 1-21.

Roschelle, J., \& Patton, C., \& Pea, R. (2002). To unlock the learning value of wireless mobile devices, understand coupling. In M. Milrad, U. Hoppe, \& Kinsuk (Eds.), Proceedings of the 2002 IEEE International. Workshop on Wireless and Mobile Technologies in Education (WMTE), 2-6.

Roschelle, J., Sharples, M., \& Chan, T. W. (2005). Introduction to the special issue on wireless and mobile technologies in education. Journal of Computer Assisted Learning, 21(3), 159-161.

Scanlon, E., Jones, A., \& Waycott, J. (2005). Mobile technologies: Prospects for their use in learning in informal science settings. [Special issue on Portable Learning: Experiences with Mobile Devices. A. Jones, A. Kukulska-Hulme, \& D. Mwanza (Eds.)]. Journal of Interactive Media in Education, December. Retrieved June 7, 2007, from http://jime.open.ac.uk/2005/25/

Savill-Smith, C., \& Kent, P. (2003). The use of palmtop computers for learning: A review of the literature. London, UK: Learning and Skills Development Agency. Retrieved June 18, 2010, from http://www.mlearning.org/docs/the use of palmtop computers for learning sept03.pdf

Shih, Y. \& Mills, D. (2007). Setting the new standard with mobile computing in online learning, The International Review of Research in Open and Distance Learning, 8(2).

Song, M. \& Zhang, S. (2008). EFM: A model for educational game design. In Z. G. Pan, X. P. Zhang, A. El Rhalibi; W. Woo, \& Y. Li (Eds.), Proceedings of Technologies for E-Learning and Digital Entertainment. Third International Conference, Edutainment, pp. 509-517. Lecture Notes in Computer Science 5093, 
Squire, K. (2010). From information to experience: Place-based augmented reality games as a model for learning in a globally networked society. Teachers College Record, 112(10), p. 9-10.

Squire, K., \& Jenkins, H. (2003). Harnessing the power of games in education. Insight, 3(1), 5-33.

Squire, K., \& Klopfer, E. (2007). Augmented reality simulations on handheld computers. Journal of the Learning Sciences, 16(3), 371 - 413.

Stein, D. (1998). Situated learning in adult education. ERIC Digest. Retrieved July 3, 2008, from http://www.ericdigest.org/1998-3/adult-education.html

Terehoff, I. I. (2002). Elements of adult learning in teacher professional development. NASSP Bulletin, $86(632), 65-77$.

Vavoula, G. N., Sharples, M., O’Malley, C., \& Taylor, J. (2004). A study of mobile learning as part of everyday learning. MLearn 2004 Book of Abstracts, July 5-6, Rome, Italy. Retrieved September 23, 2008, from http://www.eee.bham.ac.uk/vavoula/publications/MLearn04.pdf

Wagner, A. (2005). Enabling mobile learning. EDUCAUSE Review, 40(3), 40-53.

Whitton, N. (2007). Motivation and computer game based learning. In ICT: Providing choices for learners and learning. Proceedings ascilite Singapore 2007. Retrieved from http://www.ascilite.org.au/conferences/singapore07/procs/whitton.pdf

Wood, R., Lloyd, E. A. \& Ashfield, J. (2006). Student teacher perceptions of the use of mobile technologies for teaching and learning. In T. Reeves \& S. Yamashita (Eds.), Proceedings of World Conference on E-Learning in Corporate, Government, Healthcare, and Higher Education 2006 (pp. 2670-2674). Chesapeake, VA: AACE

Young, J. R. \& Upitis, R. (1999). The microworld of Phoenix quest: Social and cognitive considerations, Education and Information Technologies, 4(4), 391-408

Yuen, S. C.-Y., \& Yuen, P. K. (2008). Mobile learning. In L. A. Tomei (Ed.), Encyclopedia of information technology curriculum integration. Hershey, PA.: Idea Group.

Zurita, G., \& Nussbaum, M. (2004). A constructivist mobile learning environment supported by a wireless handheld network. Journal of Computer Assisted Learning, 20, 235-243.

\section{Biography}

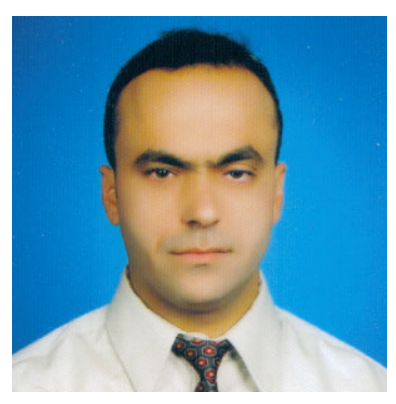

Muhammet Demirbilek is an Assistant Professor of Educational Technology at Suleyman Demirel University (SDU) in Turkey. He worked as a post doctoral researcher at Games, Learning, and Society (GLS) group in the Educational Communications and Technology division of Curriculum and Instruction at the University of WisconsinMadison. He was a former head of Informatics Department and Vice Dean of Faculty of Technical Education at SDU.

Demirbilek earned his doctorate and masters degree in Educational Technology program at the University of Florida. He also holds B.S. and MS degrees in electronics engineering. He worked on the PT3 project and served as a graduate assistant in the School of Teaching and Learning at the University of Florida.

His dissertation research examined the effects of different modes of human-computer interfaces and individual differences on user disorientation and cognitive load in hypermedia learning environments. His current research interests include the impact of mobile media and digital games and simulations on teaching and learning; relationship between second language learning achievement and game play. How the electronic game environment helps adult players to learn? and designing digital learning environments. 